\title{
Effective Gas Exchange in Paralyzed Juvenile Rabbits Using Simple, Inexpensive Respiratory Support Devices
}

\author{
ROBERT M. DIBLASI, JAY C. ZIGNEGO, CHARLES V. SMITH, THOMAS N. HANSEN, AND C. PETER RICHARDSON
}

Center for Developmental Therapeutics, Seattle Children's Research Institute, Seattle, Washington; Department of Pediatrics, University of Washington School of Medicine, Seattle, Washington, 98101

\begin{abstract}
We have developed two devices: a high-amplitude bubble continuous positive airway pressure (HAB-CPAP) and an inexpensive bubble intermittent mandatory ventilator (B-IMV) to test the hypotheses that simple, inexpensive devices can provide gas exchange similar to that of bubble CPAP (B-CPAP) and conventional mechanical ventilation (CMV). Twelve paralyzed juvenile rabbits were intubated, stabilized on CMV, and then switched to CPAP. On identical mean airway pressures (MAPs), animals were unable to maintain pulse oximeter oxygen saturation $\left(\mathrm{SpO}_{2}\right)>80 \%$ on conventional B-CPAP, but all animals oxygenated well $(97.3 \pm 2.1 \%)$ on HAB-CPAP. In fact, arterial partial pressures of $\mathrm{O}_{2}\left(\mathrm{PaO}_{2}\right)$ were higher during HAB-CPAP than during $\mathrm{CMV}(p=0.01)$. After repeated lung lavages, arterial partial pressures of $\mathrm{CO}_{2}\left(\mathrm{PaCO}_{2}\right)$ were lower with B-IMV than with CMV $(p<0.0001)$, despite identical ventilator settings. In lavaged animals, when HAB-CPAP was compared with $\mathrm{CMV}$ at the same MAP and $100 \% \mathrm{O}_{2}$, no differences were observed in $\mathrm{PaO}_{2}$, but $\mathrm{PaCO}_{2}$ levels were higher with HAB-CPAP $(70 \pm 7$ versus $50 \pm 5 \mathrm{~mm} \mathrm{Hg} ; p<0.05)$. Arterial blood pressures were not impaired by HAB-CPAP or B-IMV. The results confirm that simple inexpensive devices can provide respiratory support in the face of severe lung disease and could extend the use of respiratory support for preterm infants into severely resourcelimited settings. (Pediatr Res 68: 526-530, 2010)
\end{abstract}

$I^{n}$ nfant mortality caused by respiratory distress syndrome in the United States decreased from 268 in 100,000 live births in 1971 to 98 in 100,000 live births in 1985 (1) and 17 in 100,000 live births in 2007 (2). The decrease in mortality from 1971 to 1985 was, in large part, due to the development and widespread availability of mechanical ventilators and continuous positive airway pressure (CPAP) devices designed to assist lung recruitment and gas exchange in newborn infants in respiratory distress. However, $>4$ million infants die throughout the world each year, with 1 million dying principally from respiratory insufficiency $(3,4)$, largely because of the lack in resource-limited countries of the respiratory sup-

Received April 7, 2010; accepted August 10, 2010.

Correspondence: Robert M. DiBlasi, Center for Developmental Therapeutics, Seattle Children's Research Institute, 1900 Ninth Avenue, Seattle, WA 98101; e-mail: robert.diblasi@seattlechildrens.org

Supported by the Seattle Children's Research Institute.

Patent applications concerning the devices described in this manuscript have been submitted to USPTO (US Provisional Patent Application Numbers 61/044,002 61/ 150,670) and to International Patent Application (PCT/US2009/039957) by Seattle Children's Research Institute (SCRI). The applications are in review. Authors R.M.D., J.C.Z., C.V.S., T.N.H., and C.P.R. are inventors on the patent applications and could benefit financially from the inventions. http://www.wipo.int/pctdb/en/ wo.jsp?WO=2009126739. port devices and technologies that are commonly used in more affluent societies.

Modern ventilators are expensive to purchase, which limits availability in resource-limited countries. Even if the devices are donated, the need for highly trained personnel to operate, maintain, and repair the ventilators effectively prevent significant use of modern ventilators in most facilities. Practical methods for respiratory support of prematurely born infants could save hundreds of thousands of newborn lives each year.

In an effort to bridge the gap between the need for less expensive, simpler, more practical approaches to respiratory support and the need for greater range of simple support methods, we have developed two novel devices that can be used separately or together to provide a broad range of respiratory support for infants.

One device, termed high-amplitude bubble continuous positive airway pressure (HAB-CPAP), is capable of providing respiratory support substantially greater than is provided by bubble CPAP (B-CPAP). In a previous study, we demonstrated that HAB-CPAP could provide noninvasive support, via nasal prongs, to spontaneously breathing, lung-lavaged juvenile rabbits, with lower work of breathing and higher $\mathrm{PaO}_{2}$ levels than were observed in the same animals supported with B-CPAP at identical mean airway pressures (MAPs) (5).

The second novel device is an inexpensive, simple to operate ventilator that functions similar to the first-generation infant ventilators used in the United States in the 1970s and 1980s. In addition to providing intermittent mandatory ventilation (IMV), our novel device includes oscillations in airway pressures (Paws) during the exhalation cycle.

The purpose of the studies described in this report was to determine the capabilities of HAB-CPAP and ventilator, alone

\footnotetext{
Abbreviations: ABG, arterial blood gas analyses; B-CPAP, bubble CPAP; B-IMV, bubble intermittent mandatory ventilation or ventilators; B-IMV0, B-IMV with PEEP bubbler angle of 0; B-IMV90, B-IMV with PEEP bubbler angle of 90; B-IMV135, B-IMV with PEEP bubbler angle of 135; CPAP, continuous positive airway pressure; CMV, conventional mechanical ventilation; $\mathbf{F i O}_{2}$, fraction of inspired oxygen; HAB-CPAP, high-amplitude bubble CPAP; HAB-CPAP0, HAB-CPAP with bubbler angle of $0^{\circ}$, functionally equivalent to conventional B-CPAP; HAB-CPAP90, HAB-CPAP with bubbler angle of $90^{\circ}$, parallel with the surface of water; HAB-CPAP135, HABCPAP with bubbler angle of $135^{\circ}$; IMV, intermittent mandatory ventilation; MAP, mean airway pressures; Paw, airway pressures; PEEP, positive endexpiratory pressure; SNK, Student-Newman-Keuls; $\mathbf{S p O}_{2}$, pulse oximeter oxygen saturations
} 
and combined, to oxygenate and ventilate sedated and paralyzed juvenile rabbits. The animals were studied before and after extensive lung lavage to deplete pulmonary surfactant and thereby mimic the surfactant deficiency observed in prematurely born human infants.

\section{METHODS}

High-amplitude B-CPAP. The HAB-CPAP device, which has been described in greater detail previously (5), is similar to a B-CPAP device, with the modification that the angle of the gas exit tubing, or bubbler, can be adjusted (Fig. 1). With the bubbler exit tubing directed straight down into the water, which we designate bubbler angle $0^{\circ}$, the device is functionally equivalent to conventional B-CPAP. The abbreviations HAB-CPAP0, HABCPAP90, and HAB-CPAP135 designate the HAB-CPAP device configured to bubbler angles of $0^{\circ}, 90^{\circ}$, and $135^{\circ}$ (Fig. 1), respectively, even though a bubbler angle of $0^{\circ}$ does not provide high-amplitude oscillations in Paw.

Bubble intermittent mandatory ventilator. The bubble intermittent mandatory ventilator (B-IMV; Fig. 2) is a simple, constant-flow device that allows spontaneous breathing in conjunction with timed (unsynchronized) positive pressure inflations. The Paw control system consists of two conduits downstream of the patient interface, separated by a pinch valve that directs system gas to exit through water seals set at different depths. With the pinch valve closed, the depth in water of the deeper conduit determines the peak inspiratory pressure (PIP) of the subject. With the pinch valve open, the gas flow selectively proceeds toward the shallower conduit, where the depth, and therefore backpressure, determines the positive end-expiratory pressure (PEEP). Pressures are measured at the patient "Y" and recorded on a personal computer. The opening and closing of the pinch valve are regulated by the time controller and can be set independently. Electronics used to control the valve included an ATmega328 microcontroller unit (Atmel Corporation, San Jose, CA) powered using an AC adapter (RadioShack, Fort Worth, TX) with $12-\mathrm{V}$ output through a power switch driving a $78055 \mathrm{~V}$ voltage regulator (Texas Instruments, Austin, TX). Respiratory rates and inspiratory times were displayed on a HD44780 Hitachi dot matrix liquid crystal display controller/ driver backlit using light-emitting diodes (Hitachi Semiconducter (America) Irving, TX).

A bias flow of air or oxygen was adjusted using a rotameter with the outflow tubing connected to a humidifier (model MR740; Fisher \& Paykel Healthcare, Auckland, NZ). The inspiratory limb of the patient/subject circuit was constructed of a 50-cm length of 4.8-mm inner diameter (ID) (7.9-mm outer diameter (OD)) Tygon tubing (Saint-Gobain, Akron, OH). A 50-cm length of 8-mm ID (11-mm OD) semirigid Tygon tubing was used for the exhalation limb of the patient/subject circuit. The fraction of inspired oxygen $\left(\mathrm{FiO}_{2}\right)$ was verified using an oxygen analyzer (Massimo, Irvine, CA). The bias flow purges the system

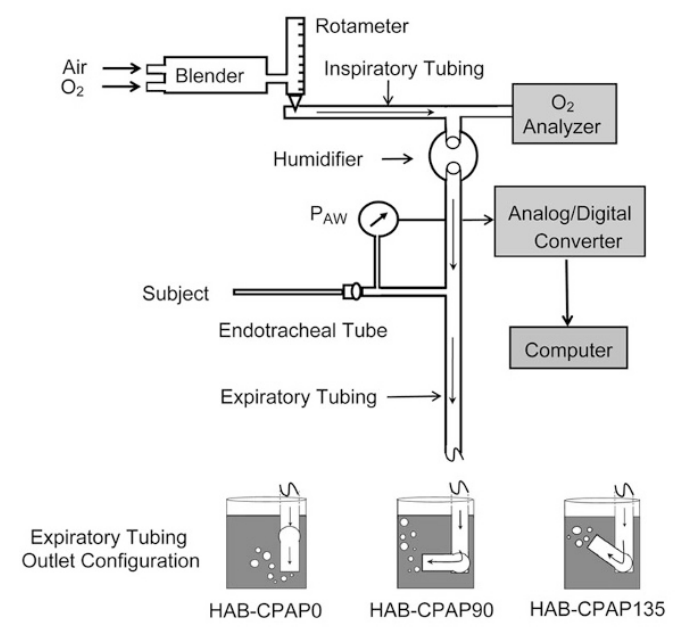

Figure 1. HAB-CPAP: bias flow of air or $\mathrm{O}_{2}$ was controlled with a rotameter connected to a semirigid circuit. A circuit " $\mathrm{Y}$ " connected the inspiratory tubing, expiratory tubing, airway pressure line, and endotracheal tube to the subject. The $\mathrm{FiO}_{2}$ levels were verified with an $\mathrm{O}_{2}$ analyzer. Paw measurements were digitally processed and stored on a computer. Gas exited the system through the water seal with the bubbler angle set at $0^{\circ}$ (HAB-CPAP0), $90^{\circ}$ (HAB-CPAP90), or $135^{\circ}$ (HAB-CPAP135).

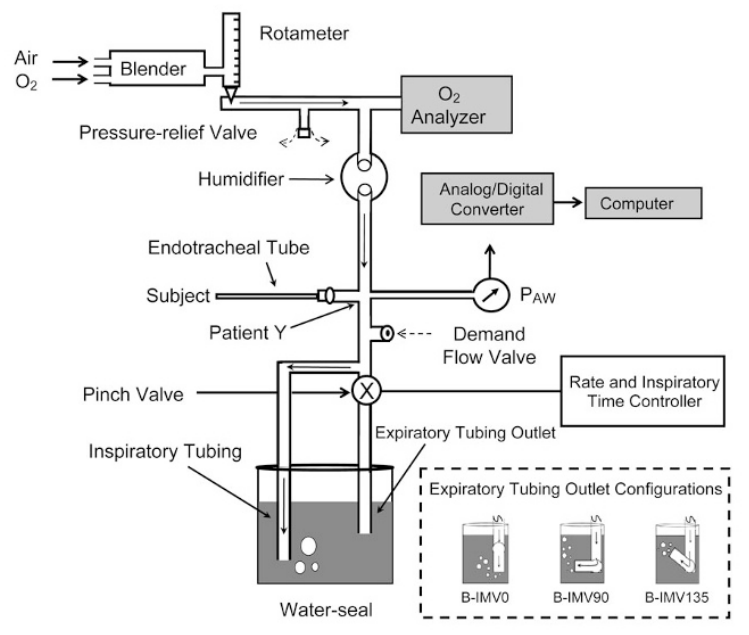

Figure 2. B-IMV: a rotameter controlled bias flows of either air or $\mathrm{O}_{2}$, and the $\mathrm{FiO}_{2}$ levels were confirmed with an in-line $\mathrm{O}_{2}$ analyzer. The patient circuit was connected to the subject via an endotracheal tube. A high-pressure relief valve was placed in line and set to $40 \mathrm{~cm} \mathrm{H}_{2} \mathrm{O}$ pressure, along with a demand flow valve that would allow room air to enter the circuit if the subject's inhalation flow was to exceed the bias flow. The pinch valve controlled the path of gas exiting the system, either through the tube placed deep in the water to control PIP or through the tube placed shallow in the water to control PEEP. The angle of the bubbler placed to control PEEP was set to $0^{\circ}$ (B-IMV0), $90^{\circ}$ (B-IMV90), or $135^{\circ}$ (B-IMV135). The user set the ventilator respiratory rates and inspiratory times, which were verified in real time using custom software analyses of the digital Paw signals.

of exhaled $\mathrm{CO}_{2}$, maintains PIP and PEEP, and functions to control the rate of pressurization during inspiration. In addition, the adjustable bubbler, used during HAB-CPAP, was attached to the expiratory limb to control the amplitude of oscillations in Paw during exhalation. When the gas exit angle of the PEEP tubing is adjusted to $0^{\circ}, 90^{\circ}$, and $135^{\circ}$, the modes are termed B-IMV0, B-IMV90, and B-IMV135, respectively (Fig. 2, inset).

The pinch valve (Fig. 2) is configured to default in the open position, so that activation failure would allow spontaneously breathing subjects to breathe against B-CPAP; subjects not breathing spontaneously would receive the level of respiratory support afforded by HAB-CPAP. An adjustable safety pop off valve provides protection against system overpressure during distal circuit occlusion. A one-way demand flow valve allows ambient gas to enter the patient circuit and avoid aspiration of water from the water seal if the subject was to inhale at a rate greater than the bias flow or if the gas supply was disrupted.

Animal preparation and instrumentation. The study protocols adhered to American Physiological Society/National Institutes of Health guidelines for humane use of animals for research and were prospectively approved by the Seattle Children's Hospital Institutional Animal Care and Use Committee. Twelve juvenile female New Zealand white rabbits (Western Oregon Rabbit Company, Philomath, OR), weighing $1.55 \pm 0.05 \mathrm{~kg}$, were anesthetized with $33 \mathrm{mg} / \mathrm{kg}$ ketamine and $6.6 \mathrm{mg} / \mathrm{kg}$ xylazine i.m. The rabbits were tracheotomized using 3.0-mm ID endotracheal tubes that were secured in place with umbilical tape to prevent displacement and leakage. Animals were ventilated on assist/control mode at 30 breaths/min, $0.35 \mathrm{~s}$ inspiratory time, and $4 \mathrm{~cm}$ $\mathrm{H}_{2} \mathrm{O}$ PEEP (Galileo; Hamilton Medical, Reno, NV). Pressure control was adjusted for tidal volumes targeted to $7 \mathrm{~mL} / \mathrm{kg}$, as measured by the ventilator proximal airway pneumotachometer. Pulse oximeter oxygen saturations $\left(\mathrm{SpO}_{2}\right.$; Massimo) and end-tidal carbon dioxide levels (Microstream; Oridion, Needham, MA) were monitored, and ventilator respiratory rates were adjusted to maintain $\mathrm{PaCO}_{2}$ between 35 and $45 \mathrm{~mm} \mathrm{Hg}$.

A 20-gauge angiocatheter was placed in the external jugular vein for administration of fluids and drugs. Maintenance i.v. fluids were provided with $3 \mathrm{~mL} / \mathrm{kg} / \mathrm{hr}$ of $0.9 \%$ saline containing $5 \%$ dextrose. Anesthesia was maintained with continuous i.v. infusion of ketamine $(10 \mathrm{mg} / \mathrm{kg} / \mathrm{hr})$ and xylazine $(4 \mathrm{mg} / \mathrm{kg} / \mathrm{hr}$ ). A 22-gauge angiocatheter was placed in the right carotid artery for arterial blood pressure monitoring and sampling for arterial blood gas analyses. A maintenance i.v. flush solution containing heparin $(0.5 \mathrm{mg} / \mathrm{kg})$ in $0.9 \%$ saline was administered at a rate of $1 \mathrm{~mL} / \mathrm{kg} / \mathrm{hr}$ to maintain catheter patency. After instrumentation, animals were paralyzed with an i.v. bolus of pancuronium bromide $(0.23 \mathrm{mg} / \mathrm{kg})$. This bolus was repeated every $3 \mathrm{~h}$ and 
supplemented if an animal exhibited spontaneous breathing efforts. Heart rates and arterial blood pressures were monitored using disposable pressure transducers attached to a monitoring system (MLT0699; AD Instruments, CO Springs, CO). Body temperatures were monitored continuously with rectal temperature probes and maintained using a warming pad.

Paw was monitored using a pressure transducer (XRA515GN; Honeywell, Morristown, NJ) at the proximal end of the endotracheal tubes, and the data were recorded via an analog/digital converter (DT9804-EC-I-BNC; Data Translation, Marlboro, MA) on a desktop computer. Paw signals were sampled at $1 \mathrm{kHz}$ and digitally processed by a fourth-order Butterworth filter with a cutoff frequency at $50 \mathrm{~Hz}$.

HAB-CPAP support of paralyzed rabbits. Figure 3 is a flow chart showing the sequence of animal experimentation. The animals were stabilized on conventional mechanical ventilation (CMV), blood was drawn for ABGs, and MAPs were calculated from Paw measurements. The animals were randomized in a crossover design to HAB-CPAP0, HAB-CPAP90, and HABCPAP135 (Fig. 2). The bias flow of air was $8 \mathrm{~L} / \mathrm{min}$, and the bubbler depth was adjusted to provide MAP equivalent to that determined for stabilization on CMV. The study design was for the paralyzed animals to be maintained for 10 min on each $\mathrm{HAB}-\mathrm{CPAP}$ bubbler angle, while closely monitoring $\mathrm{SpO}_{2}$. If the $\mathrm{SpO}_{2}$ fell below $80 \%$, the animal was returned to $\mathrm{CMV}$, until the $\mathrm{SpO}_{2}$ increased to $>95 \%$. The study was continued by changing the bubbler angle to the next angle predetermined from the randomization sequence. If the animals maintained $\mathrm{SpO}_{2}>80 \%$ for $15 \mathrm{~min}$, the condition was termed to have "passed," blood was withdrawn for ABG, and the next condition in the randomized sequence was investigated. Conditions with which the animals were unable to maintain $\mathrm{SpO}_{2}>80 \%$ for 10 min were regarded as "failed."

B-IMV support of paralyzed and lavaged rabbits. Next, the animals were returned to CMV, placed on $\mathrm{FiO}_{2} 1.0$, and lavaged with $25 \mathrm{~mL} / \mathrm{kg}$ of prewarmed $\left(38^{\circ} \mathrm{C}\right) 0.9 \%$ saline, until the animal's $\mathrm{PaO}_{2}$ remained $<100 \mathrm{~mm}$ $\mathrm{Hg}$ for $10 \mathrm{~min}$. This required from 8 to $14(9.2 \pm 0.8$, mean $\pm \mathrm{SEM})$ lavages

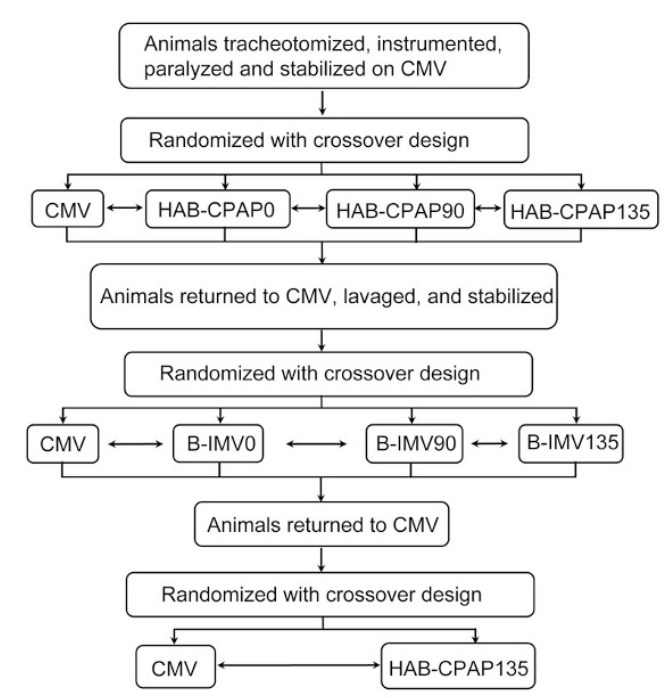

Figure 3. Flow chart of animal experiments. The scheme provides an overview of the sequence of animal preparation, initial studies with HAB-CPAP, lavage, and B-IMV, then comparison of CMV with HABCPAP135. per animal. Between lavages, the animals were stabilized on CMV for 5-10 min, until $\mathrm{SpO}_{2}$ reached $>95 \%$. After lavage, the animals were managed with tidal volumes targeted to $5 \mathrm{~mL} / \mathrm{kg}$, inspiratory time set at $0.30 \mathrm{~s}$, and PEEP at $8-9 \mathrm{~cm} \mathrm{H}_{2} \mathrm{O}$. Ventilator frequencies were adjusted to maintain $\mathrm{PaCO}_{2}$ between 45 and $50 \mathrm{~mm} \mathrm{Hg}$. After stabilization, for $\sim 15 \mathrm{~min}$, ventilator settings were recorded, and the blood was withdrawn for ABG. Next, the animals were placed, in a randomized crossover design, on B-IMV0, B-IMV90, B-IMV135, or CMV, replicating ventilator settings determined during stabilization on CMV of that animal. After $10 \mathrm{~min}$ on CMV and each of the three B-IMV conditions, blood was withdrawn for $\mathrm{ABG}$, and Paw levels were recorded digitally over a period of $15 \mathrm{~s}$.

Randomization of the sequence of the four groups (CV, B-IMV0, B-IMV90, and B-IMV135) would generate 24 sequence patterns, with $24 n$ animals required to provide $n$ animals per group; a large number of animals. We limited the number of animals for the study to 12 , and, for the selection of sequence, we created 24 pieces of paper on which each of the different sequences were written. At the start of each experiment, a piece of paper specifying the sequence to be used was pulled from an envelope. The previously drawn pieces of paper were returned to the envelope before the next drawing.

HAB-CPAP support of paralyzed and lavaged rabbits. On completion of the B-IMV studies, the animals were returned to CMV (Fig. 3). After 15 min, blood was withdrawn for ABG, and Paw levels were recorded. The animals were placed on HAB-CPAP135 for $10 \mathrm{~min}$, using MAP equivalent to that used during CMV stabilization, and ABG were measured. On completion of the studies, the animals were killed with $150 \mathrm{mg} / \mathrm{kg}$ of Euthasol.

Statistical analyses. Data are presented as means \pm SEM. Pass/fail comparisons of the paralyzed, nonlavaged rabbits on HAB-CPAP0, HABCPAP90, and HAB-CPAP135 were conducted with Cochran's $Q$ test (6). Paired $t$ tests were used for comparisons between the blood gas results obtained during HAB-CPAP135 and during CMV in the pre- and postlavaged animals. Blood gas results from the B-IMV and CMV study with lavaged animals were compared using repeated-measures ANOVA and StudentNewman-Keuls (SNK) for post hoc analyses. The data were assessed statistically by one-way repeated-measures ANOVA, with SNK post hoc, essentially assuming that the parameters for an animal on a ventilator setting were affected by the characteristics of the specific animal but less affected by the sequence of previous vent settings for that animal. Statistical analyses were made using SAS 9.1.3 (SAS Institute, Inc., Cary, NC) and SNK test, using Primer of Biostatistics 6.0 (McGraw-Hill Companies, Inc., Blacklick, OH). Statistical differences are indicated at $p<0.05$.

\section{RESULTS}

Ventilation of paralyzed rabbits by HAB-CPAP. None of the animals placed on $\mathrm{HAB}-\mathrm{CPAP0}$ sustained $\mathrm{SpO}_{2} \geq 80 \%$ for $>1$ min, and all were returned to CMV once $\mathrm{SpO}_{2}<80 \%$. Four of 12 animals sustained $\mathrm{SpO}_{2} \geq 80 \%$ (84.5 $\pm 1.6 \%, n=$ 4) for $10 \mathrm{~min}$ on HAB-CPAP90. All 12 animals maintained $\mathrm{SpO}_{2} \geq 80 \%(97.3 \pm 2.1 \% ; n=12)$ for 10 min on HABCPAP135. Assessed as pass/fail results, the three HAB-CPAP treatment groups exhibited different levels of respiratory support for the rabbits $(p<0.001)$.

Typical recordings of Paw in time of the prelavaged paralyzed animals while on CMV and HAB-CPAP135 (Fig. 4A)
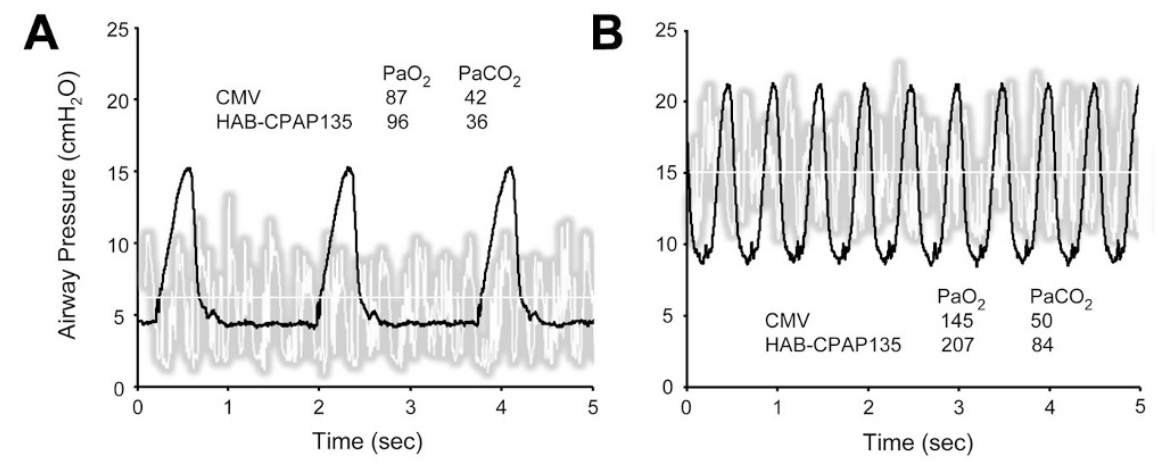

Figure 4. Superimposition of airway pressure tracings during CMV (black) and HABCPAP135 (accented white) in prelavaged $(A)$ and postlavaged animals $(B)$. The horizontal white lines represent the mean airway pressures. 

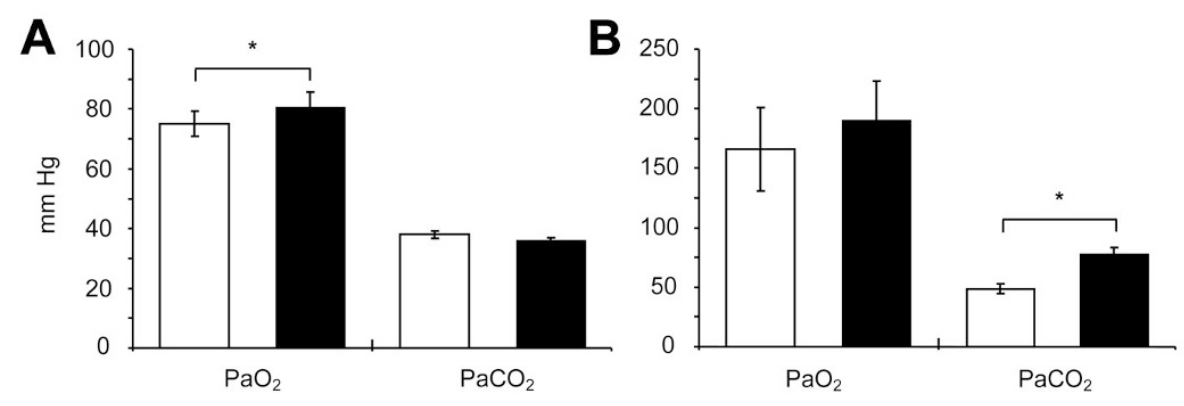

Figure 5. Oxygenation and ventilation in paralyzed and intubated rabbits supported with CMV $(\square)$ or HAB-CPAP135 (ם) in prelavaged $(A)$ animals and postlavaged $(B)$ animals. Data are means $\pm \mathrm{SEM}, n=12$; differences were assessed using paired $t$ tests; ${ }^{*} p<0.05$.

Table 1. Ventilator settings, $\mathrm{PaO}_{2}$, and arterial blood pressures of lavaged rabbits

\begin{tabular}{lcccc}
\hline \multicolumn{1}{c}{ Settings } & CMV & B-IMV0 & B-IMV90 & B-IMV135 \\
\hline PIP $\left(\mathrm{cm} \mathrm{H}_{2} \mathrm{O}\right)$ & $21.7 \pm 0.8$ & $22.2 \pm 0.6$ & $22.2 \pm 0.8$ & $22.6 \pm 0.7$ \\
$\mathrm{PEEP}\left(\mathrm{cm} \mathrm{H} \mathrm{H}_{2} \mathrm{O}\right.$ & $8.6 \pm 0.4$ & $8.4 \pm 0.3$ & $8.6 \pm 0.4$ & $8.1 \pm 0.4$ \\
$\mathrm{Rate}(\mathrm{bpm})$ & $112 \pm 3$ & $111 \pm 2$ & $111 \pm 3$ & 1.0 \\
$\mathrm{FiO}_{2}$ & 1.0 & $13.2 \pm 0.4$ & $13.8 \pm 0.4$ & 1.0 \\
$\mathrm{MAP}\left(\mathrm{cm} \mathrm{H} \mathrm{H}_{2} \mathrm{O}\right)$ & $13.5 \pm 0.3$ & $165.1 \pm 32.9$ & $140.2 \pm 19.1$ & $13.7 \pm 0.4$ \\
$\mathrm{PaO}_{2}(\mathrm{~mm} \mathrm{Hg})$ & $133.0 \pm 33.4$ & $51.6 \pm 4.8$ & $47.6 \pm 4.0$ & $128.4 \pm 22.1$ \\
$\mathrm{Blood}_{\text {pressure }}(\mathrm{mm} \mathrm{Hg})$ & $51.5 \pm 4.2$ & $51.0 \pm 5.5$ & \\
\hline
\end{tabular}

Juvenile female New Zealand white rabbits were intubated, paralyzed, and lavaged repeatedly, until $\mathrm{PaO}_{2}<100 \mathrm{~mm} \mathrm{Hg}$ was sustained on FiO ${ }_{2}$ of 1.0 . Animals were then ventilated by the four methods indicated, in a randomized crossover study. Values are mean \pm SEM, $n=12$.

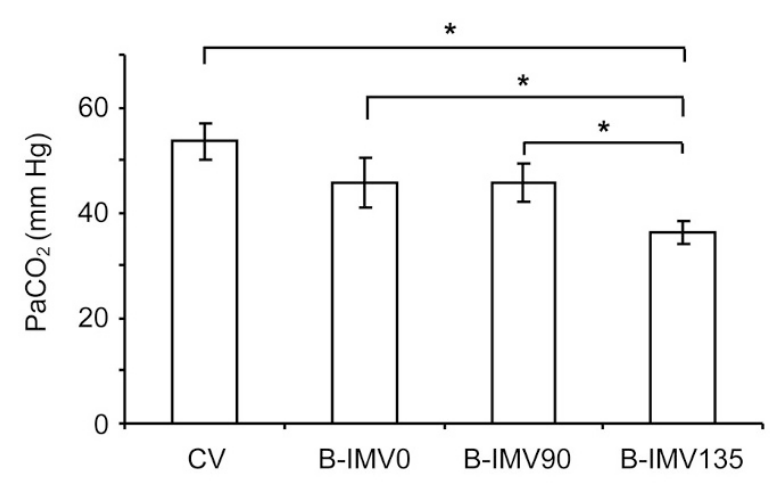

Figure 6. Ventilation with CMV and three modes of B-IMV in paralyzed, intubated, and lung-lavaged juvenile rabbits. $\mathrm{PaCO}_{2}$ levels were lower with B-IMV135 than with B-IMV0, B-IMV90, and CMV. Data are means \pm SEM, $n=12$; differences were assessed using repeated measures ANOVA, with SNK tests post hoc; $* p<0.05$.

illustrate the marked differences in profiles, despite identical MAPs. At comparable MAP for CMV and HAB-CPAP135 $\left(6.0 \pm 0.2\right.$ and $6.1 \pm 0.2 \mathrm{~cm} \mathrm{H}_{2} \mathrm{O}, n=12$, respectively), the $\mathrm{PaO}_{2}$ levels were higher $(p=0.01)$ during ventilation with HAB-CPAP135 than with CMV (Fig. 5A). The $\mathrm{PaCO}_{2}$ levels were not different $(p=0.06)$. Arterial blood pressures in the animals were higher on HAB-CPAP135 than on CMV $(50.58 \pm 3.52$ versus $45.17 \pm 2.37 \mathrm{~mm} \mathrm{Hg}, n=12$, respectively, $p<0.04$ ).

B-IMV support of paralyzed and lavaged rabbits. Following lung lavage, to reduce to $\mathrm{PaO}_{2}<100 \mathrm{~mm} \mathrm{Hg}$ on $100 \% \mathrm{O}_{2}$, and employing settings for PIP, PEEP, rates, $\mathrm{FiO}_{2}$, and MAP that were the same as those established during animal stabilization (Table 1). Following lung lavage, to reduce to $\mathrm{PaO}_{2}$ $100 \mathrm{~mm} \mathrm{Hg}$ on $100 \% \mathrm{O}_{2}$ and employing settings for PIP, PEEP, rates, $\mathrm{FiO}_{2}$, and MAP that were the same as those established during animal stabilization (Table 1), the animals

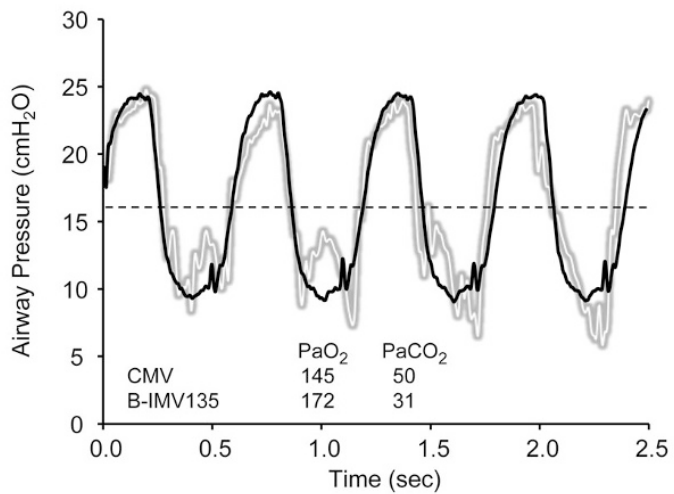

Figure 7. Superimposition of airway pressure wave forms during CMV (black) and B-IMV135 (accented white) in postlavaged animals. Horizontal dashed line represents the mean airway pressures.

exhibited no differences in $\mathrm{PaO}_{2}$ levels (Table 1) during support with CMV, B-IMV0, B-IMV90, and B-IMV135. However, $\mathrm{PaCO}_{2}$ levels of animals ventilated on B-IMV135 were lower than when managed on the other three modes of ventilation (Fig. 6). Plots of Paw wave forms of an animal on CMV and on B-IMV135 (Fig. 7), typical of those observed in the studies, illustrate the similarities in major pressure waves in the two modes and the smaller fluctuations induced by the HAB modification to B-IMV135.

Although not powered to test the hypothesis that $\mathrm{PaCO}_{2}$ levels were independent of sequence, we examined this necessary working assumption and noted that nine of 10 animals in which B-IMV135 followed one of the other three settings showed decreases in $\mathrm{PaCO}_{2}$ levels (net change, $-10.6 \pm 3.0$ $\mathrm{mm} \mathrm{Hg}$, mean $\pm \mathrm{SEM}, n=10$ ). In the single animal in which $\mathrm{PaCO}_{2}$ was greater than at the preceding setting, the difference was only $1 \mathrm{~mm} \mathrm{Hg}$. By Wilcoxon signed-rank test, an effect of B-IMV135 on decreasing $\mathrm{Paco}_{2}$ was indicated, at $p=0.02$. Conversely, changing from B-IMV135 to one of the other 
three settings was accompanied with a rise in $\mathrm{PaCO}_{2}(11.6 \pm$ $2.8 \mathrm{~mm} \mathrm{Hg}, n=9$ ), the lone decrease being by $2 \mathrm{~mm} \mathrm{Hg}, p=$ 0.02 , by Wilcoxon ranked-sign test. Blood pressures of the rabbits did not differ during management with the four modes of ventilation (Table 1).

HAB-CPAP support of paralyzed and lavaged rabbits. With MAP determined for each lavaged animal during stabilization on CMV, HAB-CPAP135 gave levels of $\mathrm{PaO}_{2}$ not different $(p>0.6)$ from those observed with CMV. However, $\mathrm{PaCO}_{2}$ levels were higher $(p=0.001)$ with HAB-CPAP135 than with CMV (Fig. 5B). The $\mathrm{PaCO}_{2}$ levels were $<65 \mathrm{~mm} \mathrm{Hg}$ in four of the 12 rabbits supported by HAB-CPAP135. Arterial blood pressures in animals supported with $\mathrm{CMV}$ and HAB-CPAP135 were not different $(44.4 \pm 5.3$ and $48.4 \pm 4.8$ $\mathrm{mm} \mathrm{Hg}, n=12$, respectively; $p=0.34$ ).

\section{DISCUSSION}

The HAB-CPAP and B-IMV devices described in the current studies offer a wide range of respiratory support capabilities, including conventional B-CPAP, HAB-CPAP, and IMV with pressure oscillations imposed during exhalation that are not presently available. The B-IMV is designed for infants and toddlers, whereas many modern ventilators, albeit expensive and complicated to operate, are capable of ventilating patients of all sizes and of providing other modes of support, such as synchronized IMV and pressure support. However, the simplicity in design of the devices described in this report will allow these devices to be manufactured far less expensively $(\leq 10 \%)$ than the combined infant/adult ventilators used on infants presently. Furthermore, the simplicity of operation of these devices will require substantially lower levels of training for use and maintenance, thus rendering these technologies far more suitable for applications in resource-limited regions than are the ventilators presently available.

The ventilation of intubated and paralyzed juvenile rabbits by HAB-CPAP135, observed in these studies (Fig. 5A), complements our previous observations that HAB-CPAP135 provided sufficient respiratory support through nasal prongs to nonparalyzed rabbits, some of which became apneic (5). The apneic animals in the previous studies were not hypocarbic or otherwise unusual in blood gases, blood pressure, and heart rate. The data presented previously and in this report indicate that HAB-CPAP provides considerable ventilation, either through nasal prong interfaces or through endotracheal tubes. The failure of HAB-CPAP0 and HAB-CPAP90 to ventilate the paralyzed rabbits in our studies is also consistent with previous reports of others $(7,8)$ who observed limited or insufficient ventilation using standard B-CPAP. The additional gas movement provided by the higher amplitude pressure fluctuations caused by the action at the bubbler air-water interface of the HAB-CPAP135 seems to be pivotal to the capabilities of this device.
The contributions of HAB-CPAP to ventilation of juvenile rabbits, either intubated (present data) or through nasal prongs (5), are evident, but the mechanisms through which these contributions arise are not defined by the data presently available. Furthermore, the adequacy of these devices and technologies for safe and effective respiratory support and ventilation of human infants, particularly premature infants with developmentally immature lungs, have yet to be determined. Additional limitations of this study design arise from the inherent instability of the lavaged juvenile rabbit lung model, as opposed to the developmental immaturity of the lungs of premature infants.

By reducing complexity and lowering purchase and operational costs, the ventilator we describe can extend the use of respiratory support into even severely resource-limited settings. As such, the comparable ventilation provided by this device indicates further investigation and development. The results demonstrate that the HAB-CPAP component applied during exhalation adds utility to IMV and suggest that smaller inflation pressures and/or lower ventilatory rates may be sufficient to deliver comparable ventilation while managed on B-IMV135 than with CMV. The ability of the complex and variable pressure fluctuations to interact with the similarly complex and variable structural characteristics of the lung airways $(9,10)$, possibly through processes related to stochastic resonance (11), may provide significant advantages to respiratory support of infants. Extending the functional capabilities of B-CPAP by the HAB modifications should make possible avoidance of endotracheal intubation and invasive ventilation, thereby improving outcomes in a greater fraction of prematurely born infants in hospitals and healthcare facilities at all levels of resource availability.

\section{REFERENCES}

1. Singh GK, Yu SM 1995 Infant mortality in the United States: trends, differentials, and projections 1950 through 2010. Am J Public Health 85:957-964

2. Heron M, Sutton PD, Xu J, Ventura SJ, Strobino DM, Guyer B 2010 Annual summary of vital statistics: 2007. Pediatrics $125: 4-15$

3. Lawn JE, Cousens S, Zupan J 20054 million neonatal deaths: when? Where? Why? Lancet 365:891-900

4. Singhal N, Bhutta ZA 2008 Newborn resuscitation in resource-limited settings. Semin Fetal Neonatal Med 13:432-439

5. DiBlasi RM, Zignego JC, Tang DM, Hildebrandt J, Smith CV, Hansen TN, Richardson CP 2010 Noninvasive respiratory support of juvenile rabbits by highamplitude bubble continuous positive airway pressure. Pediatr Res 67:624-629

6. Zar JH 1984 Biostatistical Analysis. Prentice-Hall, Englewood Cliffs, NJ

7. Reyburn B, Li M, Metcalfe DB, Kroll NJ, Alvord J, Wint A, Dahl MJ, Sun J, Dong L, Wang ZM, Callaway C, McKnight RA, Moyer-Mileur L, Yoder BA, Null DM, Lane RH, Albertine KH 2008 Nasal ventilation alters mesenchymal cell turnover and improves alveolarization in preterm lambs. Am J Respir Crit Care Med 178:407-418

8. Versmold HT, Brunstler I, Schlosser C 1982 High Frequency Oscillation Durch Blubber-CPAP Beschleunigt $\mathrm{CO}_{2}$ Elimination. Thieme, Stuttgart, Germany, pp $159-162$

9. Randell SH, Mercer RR, Young SL 1990 Neonatal hyperoxia alters the pulmonary alveolar and capillary structure of 40-day-old rats. Am J Pathol 136:1259-1266

10. Randell SH, Mercer RR, Young SL 1989 Postnatal growth of pulmonary acini and alveoli in normal and oxygen-exposed rats studied by serial section reconstructions. Am J Anat 186:55-68

11. Pillow JJ, Travadi JN 2005 Bubble CPAP: is the noise important? An in vitro study. Pediatr Res 57:826-830 